\title{
El enfoque y rol del ingeniero industrial para la gestión y decisión en el mundo de las organizaciones
}

\begin{abstract}
RESUMEN
El objetivo del presente estudio es mostrar la perspectiva sistémica del ingeniero industrial para la toma de decisiones derivadas del nuevo rol gerencial ante los retos del entorno y las orientaciones diversas para la percepción de problemas, elección de alternativas y optimización de los resultados.

Existen diversas orientaciones para enfocar a la empresa, las que se orientan hacia un aspecto parcial, planteando soluciones incompletas debido a una sesgada definición de problema. Estos son estructura, proceso, persona y momento, la primera incluye técnicas que llevan a resultados óptimos, la segunda considera la funcionalidad, comprende a los clásicos, neoclásicos, proceso estratégico, la tercera considera las relaciones humanas, la conducta, gestión del conocimiento, la última comprende el cambio, desarrollo organizacional, evolución e innovación tecnológica, contingencia y estrategia.

El nuevo entorno requiere que la gestión de las organizaciones contemple integralmente a las dimensiones que afectan el funcionamiento y los resultados. El enfoque holístico de la Ingeniería Industrial, brinda el marco conceptual para la indagación de problemas, identificación de situaciones problemáticas, criterios de evaluación y elección, decisión e implantación de acciones, lo cual lleva a resultados esperados y a resultados emergentes, sean sinergias o fallas.
\end{abstract}

Palabras clave: Enfoques de gestión, visión y misión, resolución de problemas, rol de gestión

THE SCOPE AND ROLE OF INDUSTRIAL ENGINEER FOR MANAGEMENT AND DECISION AT WORLD OF ORGANIZATIONS

\section{ABSTRACT}

The aim of this study is to show the systemic perspective of the industrial engineer for decision making arising from the new managerial role and the challenges of environment and different orientations to the perception of problems, choice of alternatives and optimization of results.

There are several directions to focus the company, they are structure, process, person and time, the first includes techniques that lead to optimal results, the second considers the functionality, comprises the classical, neoclassical, strategic process, the third considers human relationships, behavior, knowledge management, the latter comprises the change, organizational development, evolution and technological innovation, contingency and strategy. They cater to partial, suggesting incomplete solutions due to a skewed definition of problem.

The new business environment, it requires the management of organizations deal comprehensively with the dimensions and elements that affect performance and results. In this sense, the holistic approach of industrial engineer, provides a conceptual framework for the investigation of problems, identification of problematic situations, evaluation criteria and choice, decision and implementation of actions leads to expected results, depending on the lens and results emerging, synergies or failures.

Keywords: Management approach, vision and mission, problem solving, role of management

\section{INTRODUCCIÓN}

El objetivo del presente estudio es mostrar la perspectiva sistémica del ingeniero industrial para la toma de decisiones derivadas del nuevo rol gerencial ante los retos del entorno y las orientaciones diversas para la percepción de problemas, elección de alternativas y optimización de los resultados.

Tomar una decisión implica elegir entre varias opciones sobre una infinidad de temas. Prácticamente toda la vida de una persona es una secuencia de decisiones concatenadas, con diferentes grados de complejidad y de efecto. Resolver problemas también implica elegir, la diferencia es la finalidad de la elección, que es impedir un futuro efecto indeseado o cambiar una situación problemática ya existente. En este sentido, la toma de decisiones es más amplia que la resolución de problemas, aunque esta comprende pasos adicionales para la acción que la primera no considera (1). La primera cuestión es decidir entre elegir ahora o postergar, con lo que se establece, desde el inicio, el grado de compromiso con la organización y los resultados. Esta elección implica asumir responsabilidad con las metas de la empresa o, por el contrario, asumir actitud pasiva ante los eventos.

Tomar decisiones requiere técnicas administrativas que se aplican según el nivel de resolución de los problemas. El ámbito de la organización y la función empresarial dependen en gran medida de la orientación básica del decisor hacia la estructura e inversiones, el proceso y resultados, la persona y motivos, o el cambio y desarrollo. Los procesos de decisiones y resolución de problemas presentan variaciones, según el nivel del problema, el criterio y especialización del decisor y la circunstancia que rodea la problemática.

\section{ENFOQUES PARALAGESTIÓNDE LAS ORGANIZACIONES}

Los modelos de gestión han sido desarrollados y son aplicados por las comunidades académicas y empresariales, cuyas concepciones se orientan hacia un aspecto parcial de la situación, sobre la cual fijan su análisis, realizan la definición del problema, delimitan su campo de actuación y restrinjan (inconscientemente) el modo y alcance de sus decisiones (3).

Adolfo Oswaldo Acevedo Borrego, profesor FII -UNMSM; aacevedo@speedy.com.pe Martha Carolina Linares Barrantes, profesor de postgrado FISI-UNMSM; klinares@speedy. com.pe 


\subsection{Las orientaciones en la gestión de organi- zaciones}

El primer enfoque de la estructura y la organización surge desde los albores de la civilización, las primeras manifestaciones se encuentran en los sumerios (4000 A.C.), que organizan las primeras ciudadesestado gobernadas por una estructura jerárquica sacerdotal, que combinaba la construcción de diques, canales, silos y templos con la administración de tributos, el Código de Hammurabi contiene elementos de decisión para conflictos entre personas y retribución por empleo de los bienes (terreno de cultivo, animales y esclavos) y el dinero. El antecedente moderno para el manejo de las decisiones se ubica en los precursores de la escuela clásica de administración científica (Taylor) definiendo los elementos de la tarea y el método científico para la solución de problemas, donde el elemento humano es un componente del sistema de trabajo. A partir de este, surgieron y se desarrollaron las escuelas administrativas con énfasis en las variables relevantes de la decisión. La característica era el sesgo de las decisiones, de manera que se resolvía un problema pero se generaban nuevos no contemplados que, en la práctica, eran relegados o minimizados por los decisores (figura 1).

A inicios del siglo $X X$ se plantea la teoría de la burocracia de Weber, de la que derivan la escuela estructuralista y la corriente de la contingencia que enfocan el ambiente y las fuerzas del entorno que afectan la organización. Por otro lado, surge la escuela matemática y la teoría matemática de la decisión, desarrollando las técnicas de investigación de operaciones, la elección en condiciones de certeza, riesgo e incertidumbre, el control estadístico de calidad, el control gerencial por ratios y el tablero de mando integral o Balance Score Card (BSC). Los aportes actuales se enfocan en la elaboración de modelos de investigación de operaciones para la asignación de recursos y rentabilidad, apoyados por medios informáticos.

El enfoque hacia el proceso industrial empieza con la Revolución Industrial y los estudios de Taylor (14), incluye la Escuela del Proceso Administrativo de Fayol, los neoclásicos con la departamentalización y organización, las funciones especializadas como operaciones, marketing, finanzas, entre otras; la administración por objetivos de Drucker, la planeación y el proceso estratégico de Mintzberg, también la Ingeniería Industrial con la gestión de operaciones, procesos de manufactura, automatización industrial. Se consideran las modas como TQM, teoría de restricciones, reingeniería, la corriente emprendedora y los empíricos (Ford, Sloan,
Laccoca, Jobs, Gates). Estudios recientes se refieren a la concepción de Ingeniería Industrial (Blair \& Whitson),que definen al SAH o Sistema de Actividad Humana como el medio en el que los hombres combinan cooperativamente sus esfuerzos, utilizando herramientas y máquinas para alcanzar metas (6). La concepción sociotécnica de Vaill (21) identifica a los elementos de la unidad básica de trabajo dentro de los sistemas de tarea hombremáquina. Se incluyen los trabajos sobre el proceso de toma de decisiones (8), las trampas en la toma de decisiones y la visión imprescindible de Levitt acerca de la miopía en las decisiones (10).

La orientación a la persona humana tiene sus primeros antecedentes en las cartas de Pablo de Tarso que delinea la igualdad entre los hombres, retomado posteriormente por Agustín de Hipona y Calvino cuando definen que las acciones de la persona determinan su éxito o fracaso, lo que se consolida con Kant Crítica de mediante la razón práctica y Ortega y Gasset cuando define la vida como el fin de la persona humana. Modernamente, la precursora del enfoque de las personas es Mary Parker Follet quien identifica el sistema social paralelo al sistema técnico, lo que fue integrado por los estudios de Hawthorne y Tavistock mediante el concepto sociotécnico. Aparece la escuela de las Relaciones Humanas que se enfoca en la motivación y la escuela de la Conducta y del Comportamiento que definen los estilos de liderazgo como elemento clave para las decisiones enfocadas en las personas. La teoría de decisiones de Simon plantea que las decisiones conforman una cadena de decisiones, permanentes, concatenadas y relacionadas. Otros aportes relacionan el cambio con las personas, como el desarrollo de carrera de Schein y la quinta disciplina de Senge que emplea las herramientas de la teoría de sistemas para el aprendizaje organizacional (19), también el enfoque de calidad en el servicio y orientación al cliente. Se considera la concepción de modelos mentales dentro de la propuesta de la quinta disciplina (Senge) los conceptos kantianos sobre ética (Bowie) los trabajos de cultura y comportamiento (Huse y Bowditch) los cuales incluyen las facetas visible e invisible y el criterio tangible e intangible para el análisis de posición y tendencia de las variables que conforman un problema. Recientemente se están desarrollando modelos de gestión del conocimiento en las organizaciones enfocadas en el conocimiento explícito, acumulable y transmisible.

La orientación al cambio tiene sus antecedentes primeros en el devenir del Heráclito y la definición del movimiento y el cambio de Aristóteles donde las cosas son, a la vez, acto y potencia (ser y llegar a 
ser), adoptado por Newton para definir materia y energía y por Einstein para definir masa y energía o espacio-tiempo, que plantea el relativismo de las decisiones y el conocimiento. En época moderna, este enfoque se inicia con los estudios de Selznick referidos a la adaptación de la organización a las presiones del entorno, luego Von Bertalanfy desarrolló la teoría General de Sistemas que lleva los patrones de comportamiento biológico hacia el campo de las organizaciones humanas a los que denomina sistemas sociales, el enfoque se enriquece con los modelos sistémicos de Kast y Ackoff. Lewin quien consolida la visión holística e integradora de los sistemas para las decisiones en las organizaciones industriales. La primigenia concepción de sistemas (Kast y Rosenzweig) concibe a los sistemas de trabajo como procesos permanentes de superviven- cia, adaptación y crecimiento en cambio continuo, la metodología de los sistemas blandos (MSB) de Checkland plantea un renovado paradigma conceptual en la manera de enfrentar los problemas complejos, empíricamente se maneja la gestión de la innovación tecnológica por organismos supranacionales y empresas privadas, el desarrollo de las tecnologías de información y comunicación han generado el escenario de la nueva economía y la sociedad de la información, con TIC, redes, Internet, e-comercio, aún en proceso de elaboración. La creatividad, la evolución tecnológica, los innovadores conceptuales (Kelly, Porter, Senge), se aunan a los innovadores tecnológicos (empresas IBM, Intel) y los innovadores emprendedores (Bell, Gates, Jobs, Zuckerberg) para diseñar el futuro.

Figura 1. Los enfoques para la dirección en el mundo de las organizaciones

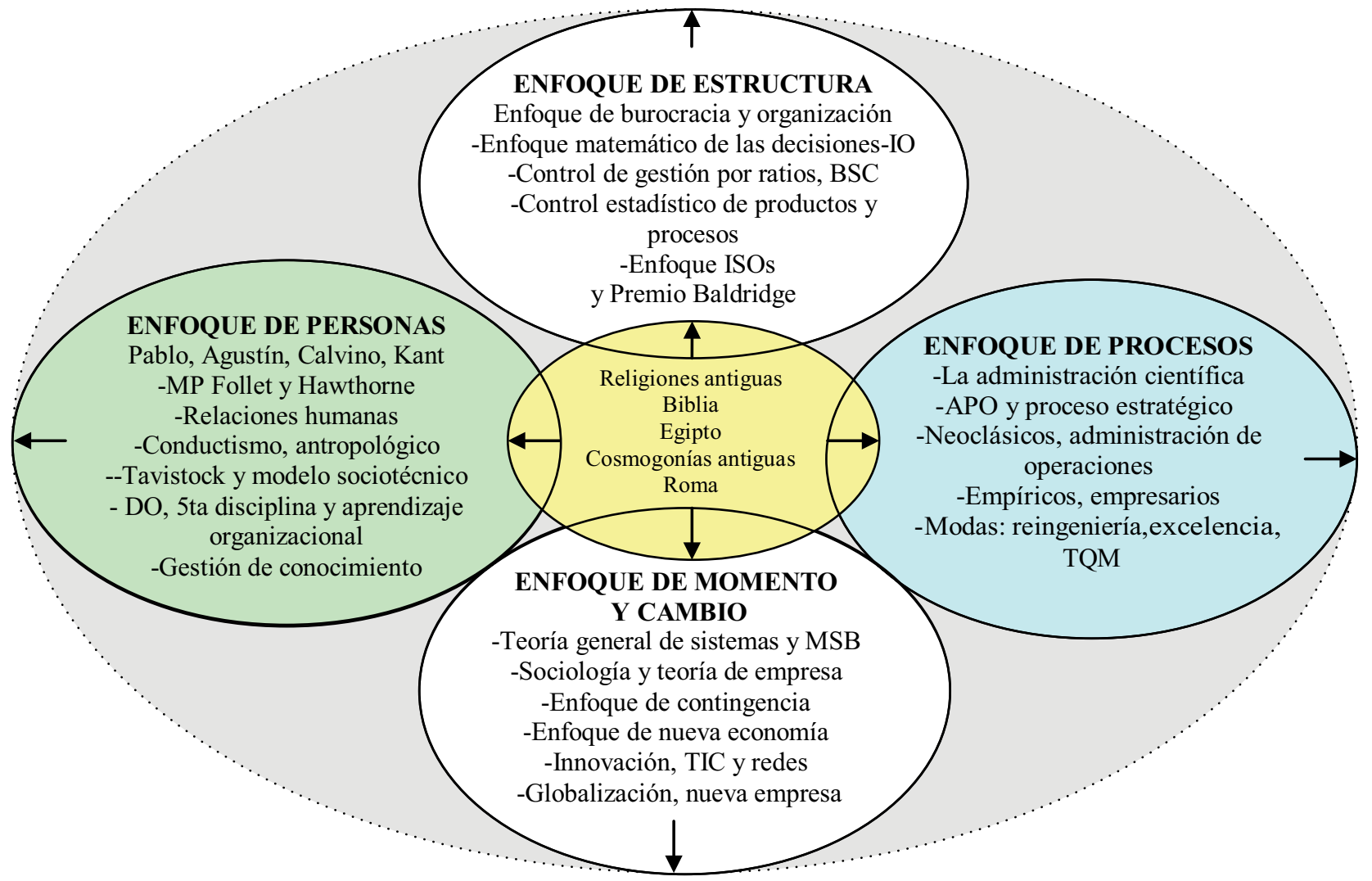


1.2 El proceso de las decisiones racionales para la resolución de problemas

El resolver problemas se sustenta en un esquema general que se deriva de la racionalidad humana, la cual establece las razones o causas para la elección y la acción de las personas. Este proceso general con variantes, según la orientación de los decisores o académicos, se muestra en el Cuadro 1.

El proceso de resolución de problemas adecuadamente implantado genera experiencia y competencias, mediante el círculo virtuoso de aprendizaje en decisiones (Figura 2).

\section{ENFOQUE DE LA INGENIERÍA INDUSTRIAL PARA LA GESTIÓN}

\subsection{La evolución histórica de la Ingeniería Industrial}

En el siglo XIX, durante el tránsito de la sociedad precapitalista y agraria con sus sistemas productivos organizados en gremios de artesanos, hacia la sociedad moderna capitalista de producción industrial y sistemas de producción masiva dentro de grandes corporaciones donde la propiedad está separada de la producción (18), se gestaron las condiciones para la aparición de los constructos iniciales de la eficiencia y máximo rendimiento del trabajador basado en la aplicación de método científico para resolver los novedosos problemas de la productividad que van surgiendo en la nuevas corporaciones.

Estos constructos encuentran su primer antecedente en la parábola de los talentos, donde el inversor (señor de la casa) asigna los recursos (talentos) según la capacidad y buena disposición de sus empleados, y las recompensas son proporcionales a los resultados (riqueza) que cada empleado aporte al inversionista. El mensaje es que los recursos que uno posee deben ser utilizados productivamente para generar mayor riqueza y compartirla con los que generaron esa riqueza, además incluye los dos elementos del mundo: las cosas ya hechas que uno recibe como dado (el ambiente, los talentos) y las personas que ejecutan el quehacer para cambiar esa riqueza inicial. El concepto de esta parábola es la eficiencia y la productividad, la cual fue asumida por Taylor y se mantiene con la profesión de la ingeniería Industrial que combina la administración de recursos (cosas) con dirección de personas (hom-

Cuadro 1. Proceso general de resolución de problemas bajo el marco de la racionalidad de las decisiones

\begin{tabular}{|l|l|}
\hline Pasos del proceso & Criterios \\
\hline $\begin{array}{l}\text { 1. Reconocer la necesidad de una de- } \\
\text { cisión para resolver una situación pro- } \\
\text { blemática }\end{array}$ & $\begin{array}{l}\text { Objetivo a alcanzar. Circunstancia y criterio de decisión } \\
\text { Rol del decisor. } \\
\text { Factibilidad y deseabilidad del proceso de resolución. }\end{array}$ \\
\hline 2. Análisis de la situación problemática & $\begin{array}{l}\text { Investigar la situación inicial. Identificar las variables pertinentes } \\
\text { Definir datos e indicadores cuantitativos y cualitativos. }\end{array}$ \\
\hline $\begin{array}{l}\text { 3. Identificar las alternativas factibles } \\
\text { para solucionar el problema, según ob- } \\
\text { jetivo }\end{array}$ & $\begin{array}{l}\text { Plantear varias alternativas (una sola opción no es elección). } \\
\text { Trabajo en grupo para redefinir propósito, fines y criterios. }\end{array}$ \\
\hline $\begin{array}{l}\text { 4. Elección de la alternativa o alternati- } \\
\text { vas deseables }\end{array}$ & $\begin{array}{l}\text { Investigación y análisis. Experimentación. } \\
\text { Contemplar la experiencia anterior en la resolución. } \\
\text { Consolidación y síntesis. Método dialéctico. }\end{array}$ \\
\hline $\begin{array}{l}\text { 5. Implantación de la alternativa elegida } \\
\text { y acciones concretas }\end{array}$ & $\begin{array}{l}\text { Asignación de recursos materiales y de responsabilidades. } \\
\text { Feedback de la solución implantada. } \\
\text { Control del avance de la ejecución mediante indicadores. }\end{array}$ \\
\hline $\begin{array}{l}\text { 6. Seguimiento de resultado y revisión } \\
\text { de efectos emergentes }\end{array}$ & $\begin{array}{l}\text { Verificar si surgen problemas emergentes (fallas). } \\
\text { Plantear decisiones adicionales oportunas (segunda oportunidad). }\end{array}$ \\
\hline 7. Aprendizaje del proceso de RP & $\begin{array}{l}\text { Feedback documentado sin feedback no se obtiene experiencia } \\
\text { (Incluso si el feedback es malo, se obtiene aprendizaje). }\end{array}$ \\
\hline
\end{tabular}

Fuente: Elaboración propia 
bres) para diseñar y crear sistemas industriales ${ }^{1}$, es decir, sistemas de actividad humana industriosos con finalidades utilitarias y de resultados económicos.
Bajo esta perspectiva, la eficiencia y la productividad representan el nexo causal para el desarrollo (Figura 3).

Figura 2. El ciclo de aprendizaje en la resolución de problemas

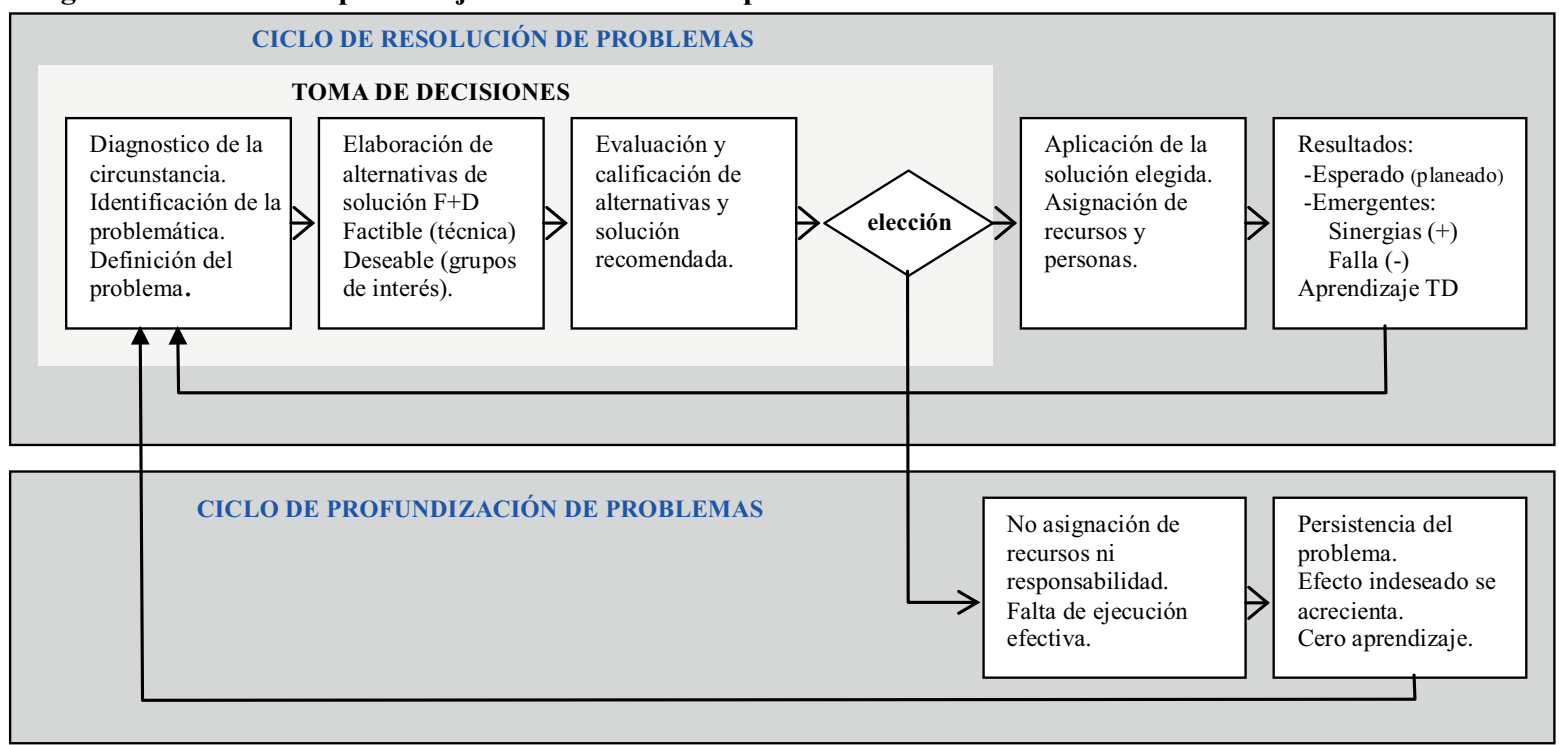

Figura 3. Marco histórico de la Ingeniería Industrial

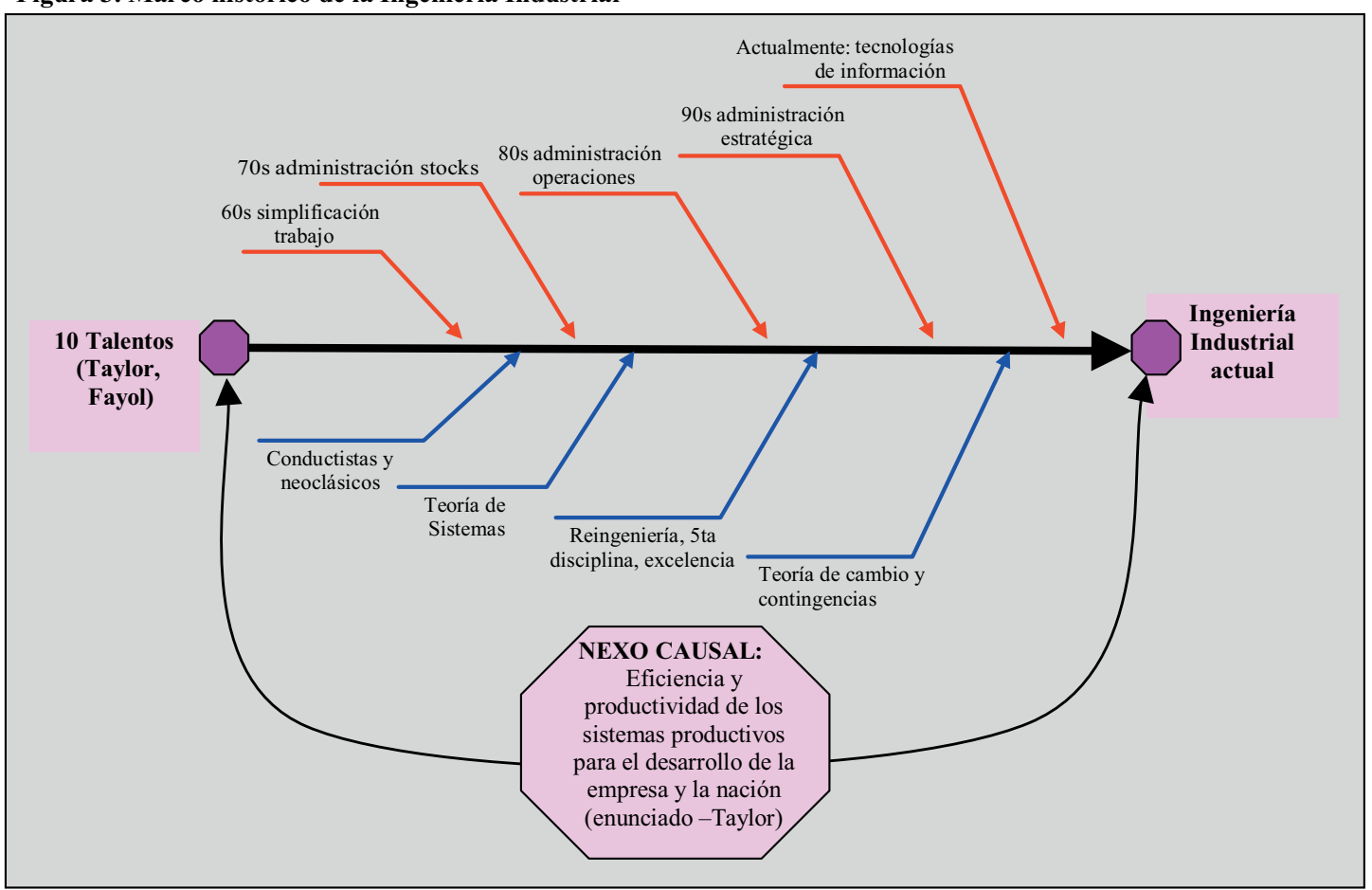

Sistemas industriales como contrapuestos a sistemas naturales, los segundos se refieren a los procesos que se dan en la naturaleza sin la intervención de la mano del hombre, los primeros se refieren a los procesos sociales de empresa, donde el hombre transforma recursos en bienes que satisfacen necesidades humanas. Esta es la concepción inicial de la ingeniería industrial, vista como una profesión encargada del diseño de sistemas de transformación de productos o de operación de servicios. En su concepción más amplia, incluye las actividades de todos los sectores industriales (bajo la definición del CIIU). 
Durante el proceso, denominado la Revolución Industrial, aparecen los precursores de la administración científica, estos primeros autores priorizan la sistematización para el buen manejo de la empresa. Adam Smith fundamenta la especialización cuando describe la fabricación de alfileres, Emerson enfatizó las operaciones eficientes y el pago de incentivos por producción, H. Ford aplicó las modernas cadenas de producción en la producción en masa. Estos autores prepararon la aparición de las bases teóricas de la administración científica (17). El primer autor clave es Frederick Taylor quien desarrolló los cuatro elementos para la máxima eficiencia de trabajadores y máquinas: el ambiente de trabajo (organización del trabajo, estandarización de herramientas, métodos de costos), el operario (selección de los empleados, enseñanza del trabajo, trabajo a plena capacidad, salarios por productividad, bonos por desempeño), el método (diseño y medición de la tareas, tarjetas de instrucción, análisis del acarreo, estudio de técnicas de trabajo) y el tiempo (análisis del trabajo, estudio de tiempos y movimientos, medición del trabajo con cronómetro, estándares de tiempo para costos de mano de obra, programación de producción y fijación de precios). Taylor sienta los fundamentos teóricos para definir la relación hombre-máquina, que deviene en el sustento y piedra angular de la Ingeniería Industrial.

El otro autor clave es Fayol quien divide las operaciones industriales y comerciales: técnicos, comerciales, financieros, administrativos, de seguridad y contable (9). Establece los 14 principios de la administración, que se orientan a las dimensiones de la empresa. Foco en la estructura: autoridad y responsabilidad, disciplina, unidad de mando, centralización, jerarquía, orden. Foco en el proceso: división del trabajo, unidad de dirección. Foco en la persona: subordinación del interés particular al interés general, remuneración del personal, equidad, espíritu de equipo. Foco en el cambio: estabilidad del personal, iniciativa. Otros autores fueron los Gilbreth quienes estudiaron los movimientos fundamentales del cuerpo humano y los micromovimientos, estos tuvieron aplicación en diversos campos de la empresa y del gobierno de Estados Unidos. Gantt estudió el adiestramiento e incentivo de los obreros, aunque su mayor aporte se refiere al control de la gestión mediante técnicas gráficas y visuales (12).

El Cuadro 2 muestra los principales hitos en el desarrollo teórico y las herramientas de la Ingeniería Industrial.

Cuadro 2. Hitos en el desarrollo de la Ingeniería Industrial

\begin{tabular}{|c|c|c|c|c|}
\hline Año/hito & Concepto & Foco de estudio & Herramientas & Autor principal \\
\hline \multicolumn{5}{|c|}{ Antecedentes y aparición de los fundamentos de la administración científica } \\
\hline \multirow[b]{2}{*}{$\begin{array}{l}\text { Fines } \\
1800 \\
\text { y } 1 \text { ra dé- } \\
\text { cada de } \\
1900\end{array}$} & $\begin{array}{l}\text { La coordinación y el con- } \\
\text { trol en la administración. }\end{array}$ & $\begin{array}{l}1^{\circ} \text { Proceso: coordinación y tarea del } \\
\text { jefe (walking around) y eficiencia. }\end{array}$ & $\begin{array}{l}\text { Registro para el control de } \\
\text { costos y fichas para pago de } \\
\text { remuneraciones }\end{array}$ & Henry Metcalfe \\
\hline & $\begin{array}{l}\text { Publicación de "Shop } \\
\text { Management" (1903). }\end{array}$ & $\begin{array}{l}\text { Proceso: siempre existe un método } \\
\text { mejor. Estructura: un lugar para } \\
\text { cada cosa y cada cosa en su lugar. } \\
\text { Persona: el puesto adecuado para la } \\
\text { persona adecuada. } \\
\text { Tiempo: estándares }\end{array}$ & $\begin{array}{l}\text { Administración científica del } \\
\text { trabajo. Estudio de trabajo, } \\
\text { programación de producción, } \\
\text { Productividad. micromovimien- } \\
\text { tos }\end{array}$ & Frederick Taylor \\
\hline \multicolumn{5}{|c|}{ Primera fase: amplio desarrollo de las bases de la administración científica } \\
\hline \multirow{4}{*}{$\begin{array}{l}\text { Años } \\
1910- \\
1920\end{array}$} & Psicología Industrial & $\begin{array}{l}\text { Proceso: análisis de operaciones de } \\
\text { la tarea del trabajador }\end{array}$ & Estudio de micromovimientos & Frank Gilbreth \\
\hline & Línea de ensamblaje & $\begin{array}{l}\text { Proceso: productividad de la produc- } \\
\text { ción en masa }\end{array}$ & Gráfica de línea de ensamble & Henry Ford \\
\hline & $\begin{array}{l}\text { Control de secuencia de } \\
\text { actividades }\end{array}$ & $\begin{array}{l}\text { Proceso: control de secuencia y tiem- } \\
\text { pos de tareas complejas }\end{array}$ & $\begin{array}{l}\text { Gráfica de programación de } \\
\text { actividades }\end{array}$ & Henry Gantt \\
\hline & Control de inventarios & Proceso: Tamaño de lote económico & $\begin{array}{l}\text { Modelo de lote económico en } \\
\text { gestión de stocks }\end{array}$ & F. W. Harris \\
\hline
\end{tabular}




\begin{tabular}{|c|c|c|c|c|}
\hline \multicolumn{5}{|c|}{ Segunda fase: aparición del enfoque humano como opuesto y complemento de la administración científica } \\
\hline \multirow{3}{*}{$\begin{array}{l}\text { Años } \\
1930 \\
{ }^{*} \text { corres- } \\
\text { ponde } \\
\text { a esta } \\
\text { fase }\end{array}$} & Control de calidad & $\begin{array}{l}\text { Proceso: control estadístico de } \\
\text { procesos }\end{array}$ & $\begin{array}{l}\text { Muestreo de inspección y tablas } \\
\text { estadísticas de control }\end{array}$ & $\begin{array}{l}\text { Shewhart, Dod- } \\
\text { ge y Romig }\end{array}$ \\
\hline & Estudios Hawthorne & Persona: motivación del trabajador & $\begin{array}{l}\text { Estudio de condiciones de } \\
\text { trabajo }\end{array}$ & Elton Mayo \\
\hline & $\begin{array}{l}\text { Estudios NewCastle * } \\
\text { (1951) }\end{array}$ & $\begin{array}{l}\text { Sistema técnico y sistema social que } \\
\text { interactúan }\end{array}$ & $\begin{array}{l}\text { Los equipos de trabajo afecta- } \\
\text { dos por la tecnología }\end{array}$ & $\begin{array}{l}\text { Trist-Instituto } \\
\text { Tavistock }\end{array}$ \\
\hline \multicolumn{5}{|c|}{ Tercera fase: desarrollo de las ciencias formales en la solución de problemas de las organizaciones } \\
\hline $\begin{array}{l}\text { Años } \\
1940\end{array}$ & Programación lineal & $\begin{array}{l}\text { Estructura: las leyes de las ciencias } \\
\text { formales aplicadas en organizacio- } \\
\text { nes }\end{array}$ & $\begin{array}{l}\text { Método simplex para la solución } \\
\text { de problemas dentro de siste- } \\
\text { mas complejos }\end{array}$ & $\begin{array}{l}\text { Grupos IO de } \\
\text { UK y Dantzig }\end{array}$ \\
\hline \multirow{2}{*}{$\begin{array}{l}\text { Años } \\
1950 \\
-1960\end{array}$} & $\begin{array}{l}\text { Investigación de opera- } \\
\text { ciones }\end{array}$ & $\begin{array}{l}\text { Estructura: aplicación de las leyes de } \\
\text { las ciencias formales en la solución } \\
\text { de problemas organizacionales }\end{array}$ & $\begin{array}{l}\text { Simulación, teoría de colas, } \\
\text { líneas de espera, teoría de las } \\
\text { decisiones, programación mate- } \\
\text { mática, PERT -CPM }\end{array}$ & $\begin{array}{l}\text { Investigadores } \\
\text { y académicos } \\
\text { de USA y } \\
\text { Europa }\end{array}$ \\
\hline & $\begin{array}{l}\text { Teoría General de Sis- } \\
\text { temas }\end{array}$ & $\begin{array}{l}\text { Cambio: las organizaciones son sis- } \\
\text { temas interdependientes jerárquicos } \\
\text { y abiertos }\end{array}$ & $\begin{array}{l}\text { Cibernética, tecnología, teoría } \\
\text { matemática, teoría de sistemas }\end{array}$ & von Bertalanffy \\
\hline \multicolumn{5}{|c|}{ Cuarta fase: desarrollo de las ciencias formales en la solución de problemas de las organizaciones } \\
\hline \multirow{2}{*}{$\begin{array}{l}\text { Años } \\
1970\end{array}$} & Computadora & $\begin{array}{l}\text { Estructura: Uso de la computadoras } \\
\text { en todos los ámbitos de las organi- } \\
\text { zaciones. }\end{array}$ & $\begin{array}{l}\text { Programación y control de taller, } \\
\text { MRP, pronósticos, gestión de } \\
\text { inventario, gestión proyectos, }\end{array}$ & $\begin{array}{l}\text { IBM Orlicky, } \\
\text { Wight }\end{array}$ \\
\hline & $\begin{array}{l}\text { Organizaciones de } \\
\text { servicios }\end{array}$ & $\begin{array}{l}\text { Proceso: producción masiva en el } \\
\text { sector de los servicios. }\end{array}$ & $\begin{array}{l}\text { Proceso administrativo en orga- } \\
\text { nizaciones de servicios }\end{array}$ & $\begin{array}{l}\text { Fast Food, } \\
\text { Retail, Banca }\end{array}$ \\
\hline \multirow{4}{*}{$\begin{array}{l}\text { Años } \\
1980\end{array}$} & Estrategia de producción & $\begin{array}{l}\text { Proceso: el proceso estratégico en la } \\
\text { creación de competitividad. }\end{array}$ & $\begin{array}{l}\text { Operaciones y la creación de } \\
\text { ventajas competitivas }\end{array}$ & $\begin{array}{l}\text { Escuela de } \\
\text { Negocios de } \\
\text { Harvard }\end{array}$ \\
\hline & $\begin{array}{l}\text { Enfoque japonés de } \\
\text { gestión }\end{array}$ & $\begin{array}{l}\text { Proceso: control total de calidad } \\
\text { (TQC) y justo a tiempo (JIT). }\end{array}$ & $\begin{array}{l}\text { Kanban, poka-Jokes, filosofía } \\
\text { de la calidad, ciclo PDCA }\end{array}$ & $\begin{array}{l}\text { Tai-Ichi Ohno, } \\
\text { Deming y Juran }\end{array}$ \\
\hline & Control de manufactura & $\begin{array}{l}\text { Estructura: automatización del con- } \\
\text { trol de procesos en fábrica. }\end{array}$ & CIM, FMS, CAD/CAM, robótica & Empresas al-tec \\
\hline & Manufactura sincrónica & $\begin{array}{l}\text { Proceso: velocidad del proceso y } \\
\text { troughput del sistema productivo. }\end{array}$ & $\begin{array}{l}\text { Teoría de restricciones, análisis } \\
\text { de cuello de botella }\end{array}$ & Goldratt \\
\hline \multirow{4}{*}{$\begin{array}{l}\text { Años } \\
1990\end{array}$} & $\begin{array}{l}\text { Administración de cali- } \\
\text { dad total }\end{array}$ & $\begin{array}{l}\text { Proceso: Calidad del servicio y } \\
\text { productividad. }\end{array}$ & $\begin{array}{l}\text { Premio Baldridge, ISO } 9000 \text {, in- } \\
\text { geniería valor, mejora continua }\end{array}$ & ANSI, ISO \\
\hline & $\begin{array}{l}\text { Reingeniería de proce- } \\
\text { sos }\end{array}$ & $\begin{array}{l}\text { Rediseño radical de los procesos } \\
\text { productivos y empresariales buscan- } \\
\text { do la máxima eficiencia. }\end{array}$ & $\begin{array}{l}\text { Análisis de procesos, análisis } \\
\text { de valor, outsourcing, resizing }\end{array}$ & Hammer \\
\hline & Empresa electrónica & $\begin{array}{l}\text { Estructura: redes de transporte de } \\
\text { comunicación de voz y datos interco- } \\
\text { nectadas mundialmente. }\end{array}$ & Internet, World Wide Web & $\begin{array}{l}\text { Netscape, AOL, } \\
\text { Microsoft }\end{array}$ \\
\hline & Cadena de suministro & $\begin{array}{l}\text { Proceso: integración del flujo de } \\
\text { información en base a redes ethernet } \\
\text { interconectadas. }\end{array}$ & $\begin{array}{l}\text { Software SAP/R3 cliente/ser- } \\
\text { vidor }\end{array}$ & SAP, Oracle \\
\hline $\begin{array}{l}\text { Primera } \\
\text { década } \\
\text { del siglo } \\
\text { XXI }\end{array}$ & Negocios electrónicos & $\begin{array}{l}\text { Estructura: red interconectada } \\
\text { e-negocios, e-gobierno, e-finanzas }\end{array}$ & $\begin{array}{l}\text { Internet, telecomunicaciones, } \\
\text { broadcasting }\end{array}$ & $\begin{array}{l}\text { Amazon, eBay, } \\
\text { America Online, } \\
\text { Yahoo!. }\end{array}$ \\
\hline
\end{tabular}

Fuente: Elaboración propia 


\subsection{Definición, visión y misión del ingeniero in- dustrial}

La Ingeniería Industrial (II) se ha potenciado desde la revolución industrial, su importancia crece por su eficaz aporte a la eficiencia y la productividad empresarial que lleva a nuevos niveles, la competitividad de los sectores industriales de los países.

La definición de Ingeniería Industrial (II) enunciada por el Instituto Americano de Ingenieros Industriales es:

"La ingeniería industrial se ocupa del diseño, la mejora y la instalación de sistemas integrados de hombres, materiales, equipos y energía. Se alimenta del conocimiento especializado y de la habilidad en las ciencias matemáticas, físicas y sociales, junto con los principios y métodos de análisis y diseño de ingeniería para especificar, predecir y evaluar los resultados que se obtendrán de esos sistemas." 2.

Anteriormente, en su libro Los principios de la Administración Científica (20), Taylor creó la fórmula para la máxima producción, en la que establece las cuatro dimensiones para la mayor productividad del trabajo (Figura 4).

"La máxima producción se obtiene cuando a un trabajador se le asigna una tarea definida para desempeñarla en un tiempo determinado y de una forma definida"3.
La visión de la Ingeniería Industrial permite vislumbrar que, en el futuro, se mantendrá la tendencia de participación en organizaciones de diferentes sectores manufactureros y de servicios. Además ha de diversificarse hacia las organizaciones empresariales emergentes, pequeña empresa y empresa global. Con el enfoque de mejora y calidad, las empresas han de mantener en su plana directiva a ingenieros industriales, dirigiendo o supervisando sus procesos, incluyendo sectores de gobierno y servicios como educación, seguridad social y salud.

La misión consensuada plantea que la II ha de ser una comunidad de conocimiento que lidere la formación de profesionales competentes, comprometidos y promotores del desarrollo de sectores industriales, grupos sociales y zonas geográficas. Mediante la formación integral de profesionales en áreas de ciencia, tecnología y gestión industrial, constituyéndose en generadores de conocimiento, promotores del desarrollo y aplicación de técnicas de la especialidad. Desarrollando estudios e investigaciones que generen valor a las personas, la empresa y la sociedad, dentro de principios éticos, excelencia profesional y calidad.

3.3 Las tendencias clave en la labor del ingeniero industrial

Las nuevas formas empresariales y los cambios tecnológicos, diluyen las fronteras de los dominios académicos y las especialidades convergen en te-

Figura 4. La administración científica de Taylor orientada al nivel operativosegúnmodelo4D(2)

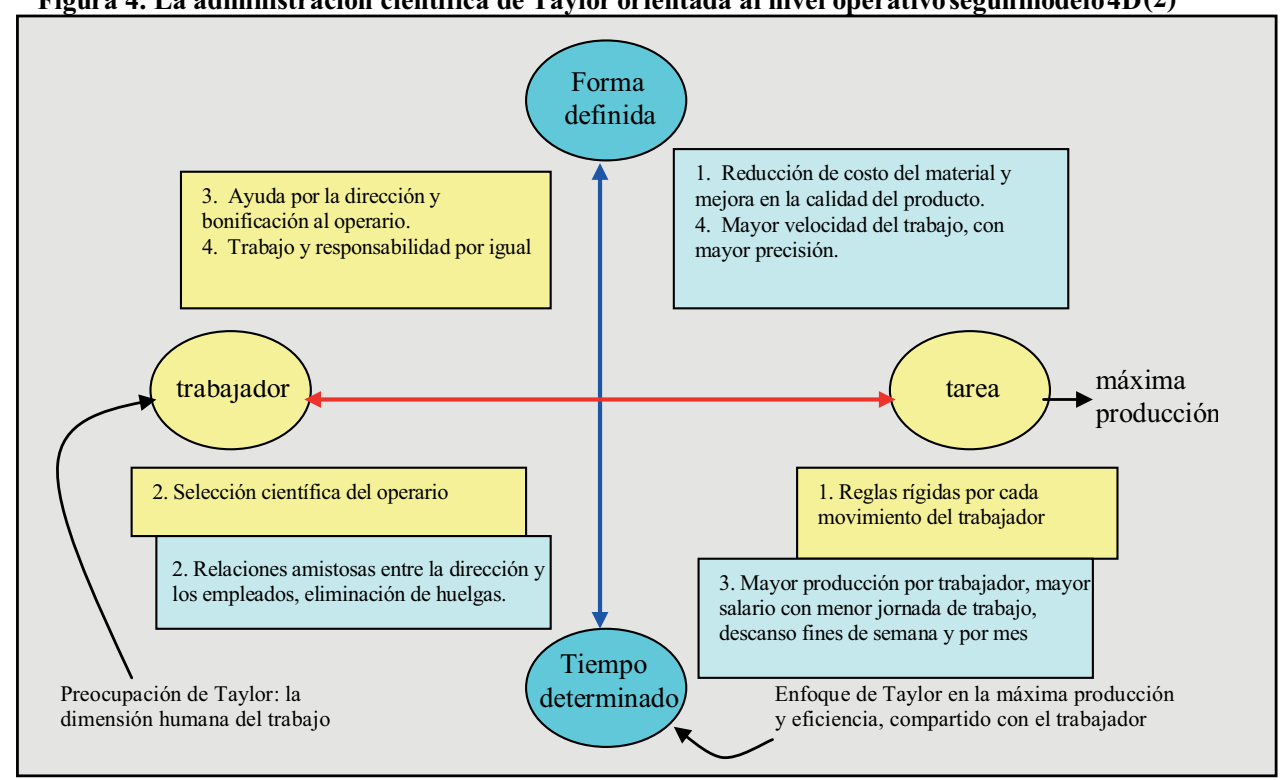

Fuente: Basado en Taylor (1961)

Zandin (2005).

Michaell Ferrell, primer presidente de H.B.Maynard Co. plantea la vigencia de la fórmula tayloriana, enfatiza que el que el trabajo debe estar bien organizado y al trabajador se le debe asignar una tarea específica y un método específico a seguir. Este planteamiento es rescatado en la cuarta edición del Manual del Ingeniero Industrial (Hodson, 1996). 
mas comunes (15). El ingeniero industrial va ampliando su alcance hacia segmentos de servicios, sectores primario-extractivos, mineros, energéticos, agrícolas, ganaderos, también a la consultoría con enfoque de negocios basado en la productividad.

Respecto al entorno, el ingeniero conforme va ampliandose el campo de su tarea ha de aplicar las razones de productividad y eficiencia. Paulatinamente, va cubriendo los procesos que surgen en las diversas situaciones problemáticas, a los que se denominan sistemas de actividad humana. La situación problemática en que ha de intervenir, ha mantenido un sostenido ritmo de creciente complejidad, presenta cuatro variantes: 1. situaciones estructuradas y rígidas, 2. situaciones flexibles y no determinísticas, 3. situaciones complejas y de resultados, 4. situaciones evolutivas y cambiantes.

Para asegurar la efectividad, como profesional o como experto consultor, Billings ${ }^{4}$, en su estudio sobre el rol del ingeniero industrial en la organización moderna, ha identificado ciertos factores clave del éxito, que se describen a continuación en el Cuadro 3.

\subsection{El marco epistemológico para entender y re- solver problemas}

El mundo de la empresa se percibe y se entiende en la mente del decisor. A partir de las percepciones de los fenómenos del mundo real, y derivado de su conocimiento y especialización personal, el ingeniero industrial, define situaciones problemáticas, entiende los problemas del entorno a través de la elaboración mental de una visión global y completa de la problemática de la organización, sobre la cual se sustenta su posterior análisis y propuestas de solución a las situaciones indeseadas (4).

A esta visión conceptual, se le denomina weltanschauung o concepción del mundo de la empresa (7), y es el paso inicial para efectuar la definición del problema e identificar los actores del escenario problemático. La Figura 5 muestra el proceso de entender la problemática de la realidad de la empresa. El marco epistemológico se basa en la síntesis como metodología de investigación (11), empleando un método de estudio constructivista, dialéctico, antropológico e histórico. Entender el mundo real permite tomar decisiones para la resolución de problemas.

Cuadro 3. Factores clave del éxito del ingeniero industrial

\begin{tabular}{|c|c|}
\hline Foco del factor & Factor \\
\hline \multirow{4}{*}{ Visión sistémica del ingeniero } & Comprender holísticamente la circunstancia,contexto de la organización y la tarea \\
\hline & $\begin{array}{l}\text { Percibir, entender, analizar e integrar los procesos reales frente a los ideales (diseña- } \\
\text { dos). }\end{array}$ \\
\hline & Diferenciar dilema vs. conflicto en la resolución de problemas (recursos y personas). \\
\hline & $\begin{array}{l}\text { Identificar las situaciones problemáticas sistémicas dentro de los sistemas de actividad } \\
\text { humana. }\end{array}$ \\
\hline \multirow{4}{*}{$\begin{array}{l}\text { Propósito y finalidad de la ca- } \\
\text { rrera }\end{array}$} & Aplicar los conceptos de la Ingeniería Industrial a la problemática del mundo real. \\
\hline & Gestionar el funcionamiento de los sistemas en operación (estabilizar y mejorar). \\
\hline & $\begin{array}{l}\text { Gestionar el cambio, evolución e innovación de sistemas (ingeniería de sistemas em- } \\
\text { presariales). }\end{array}$ \\
\hline & Enfatizar la implantación y seguimiento del mismo. \\
\hline \multirow{4}{*}{$\begin{array}{l}\text { Perspectiva para entender y } \\
\text { resolver las situaciones pro- } \\
\text { blemáticas }\end{array}$} & Ser flexible y enfocado, a la vez. \\
\hline & $\begin{array}{l}\text { Añadir lo creativo e imaginativo, superando las fronteras de la racionalidad y lógica } \\
\text { profesional. }\end{array}$ \\
\hline & Liderazgo y comunicación verbal y por escrito. \\
\hline & Toma de decisiones para res \\
\hline
\end{tabular}

Fuente: Adaptado de Billings

Billings plantea que la carrera de Ingenieria Industrial se puede sintetizar en la palabra diversidad, ya que su conceptualización involucra un extenso campo aplicativo. Billings es Director de Transporte en la Walt Disney Co. 
Tomar decisiones ha devenido en una de las actividades esenciales del trabajo del ingeniero industrial, adicional a sus tareas de diseño y mejora de los sistemas empresariales. Tomar decisiones es el reconocimiento de buscar y superar una situación indeseada, esta es fundamental para la supervivencia de la empresa como organismo social que interactúa con su ambiente. Las decisiones se enfocan desde diversas perspectivas, las cuales definen la manera en que se percibe y se afronta las situaciones problemáticas.

La resolución de problemas es el proceso de percepción de la necesidad de una decisión, analizar la situación, entender y sintetizar causas (S1) y efectos (S2), identificar problemas, efectuar la elección de una alternativa y aplicar medidas de seguimiento de los resultados (13). Así, se ha de considerar la delimitación de la circunstancia que enmarca la decisión: posición y rol del decisor, escenario productivo, criterios y herramientas de solución, antecedentes del caso y propósitos del decisor.

\section{EL ROL DEL INGENIERO INDUSTRIAL EN LA GESTIÓN EMPRESARIAL}

\subsection{El concepto de gestión de procesos}

La Ingeniería Industrial se define como la rama de la ingeniería enfocada en el diseño de sistemas de producción y en el manejo de los recursos materiales y humanos para la provisión de bienes y servicios (22). El funcionamiento eficaz, definido en fun- ción a la situación histórica concreta, depende de la adecuada conceptualización de las cosas y personas, así como tambien de la integración operacional de los recursos (inversiones, equipamiento, capital) con las personas (talento, competencias, tarea), como se visualiza en la Figura 6.

El ingeniero industrial está experimentando cambios trascendentes en su rol de gestión de recursos y personas, de manera que a las competencias técnicas de ingeniería ha de añadir nuevas competencias. Paulatinamente va ampliando su rol, de analista y diseñador de procesos y se dirige hacia los niveles de decisión estratégica, además de gestión integral y global de sistemas productivos.

\subsection{Los campos de actuación del ingeniero in- dustrial}

Desde la perspectiva académica, el ingeniero industrial desarrolla sus actividades en cuatro grandes campos:

- El campo de la experiencia y la realidad social.

- El campo de la investigación y la creación de conocimiento.

- El campo de la praxis empresarial y la resolución de problemas técnicos.

- El campo del diseño y la innovación emprendedora.

Figura 5. El proceso de percibir la problemática de la empresa

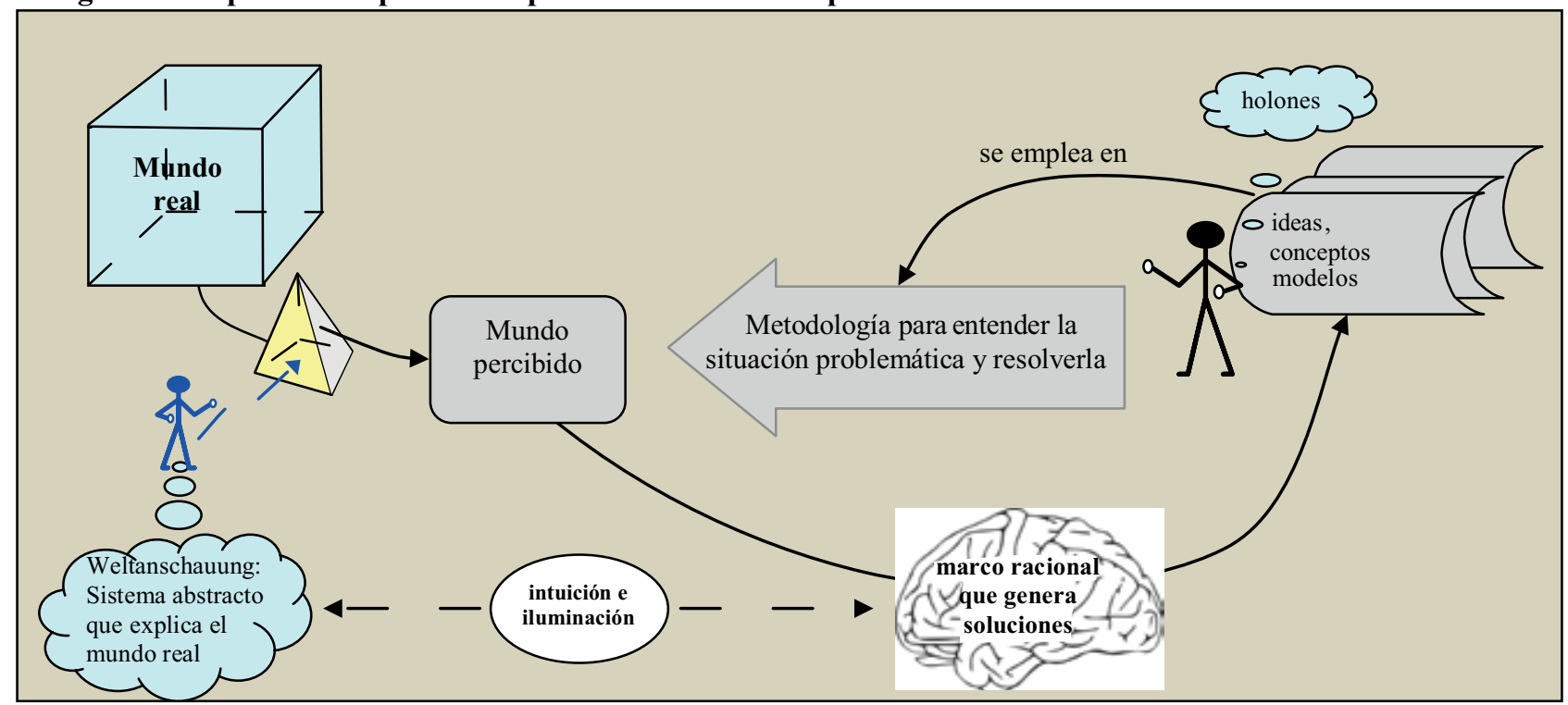


Figura 6. Cambios en el concepto de gestión de los sistemas de actividad humana

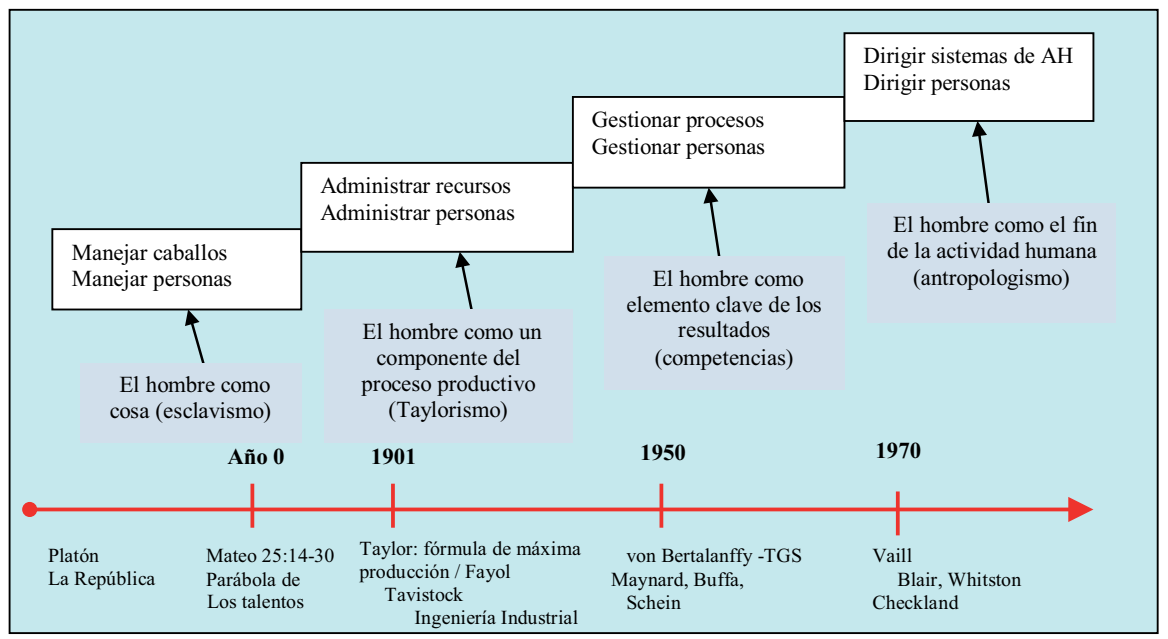

Fuente: elaboración propia

El Cuadro 4 sugiere la labor profesional en los campos de actuación y en los sistemas empresariales.

Cuadro 4. El rol del ingeniero industrial bajo la perspectiva académica

\begin{tabular}{|c|c|c|}
\hline Ámbito de acción & Rol del ingeniero industrial. Foco de actividad. & $\begin{array}{l}\text { Profesiones } \\
\text { con las que } \\
\text { compite }\end{array}$ \\
\hline \multicolumn{3}{|l|}{ Campos de actuación } \\
\hline $\begin{array}{l}\text { 1. Estudio e investigación de } \\
\text { problemas de la sociedad y } \\
\text { organizaciones empresariales }\end{array}$ & $\begin{array}{l}\text { Hipótesis de investigación sobre enigmas derivados del devenir de las organiza- } \\
\text { ciones. } \\
\text { Planeación y líneas de investigación orientadas al mejor uso de los recursos } \\
\text { materiales y humanos. }\end{array}$ & Economistas \\
\hline $\begin{array}{l}\text { 2. Innovación, diseño y desa- } \\
\text { rrollo de productos y procesos e } \\
\text { Ingeniería Humana }\end{array}$ & $\begin{array}{l}\text { Investigación de necesidades humanas, diseño de productos para cubrir estas } \\
\text { necesidades. Desarrollo de atributos y cualidades de nuevos productos y ele- } \\
\text { mentos de nuevos procesos de operación. } \\
\text { Diseño, planeación, organización e implantación de procesos empresariales } \\
\text { (producción, operación, apoyo y servicios), incluye interface hombre-máquina y } \\
\text { ergonomía. }\end{array}$ & $\begin{array}{l}\text { Ingenierías } \\
\text { agroindus- } \\
\text { triales }\end{array}$ \\
\hline $\begin{array}{l}\text { 3. Análisis y resolución de } \\
\text { problemas }\end{array}$ & $\begin{array}{l}\text { Análisis y diagnósticos empresariales, identificar limitaciones internas y ex- } \\
\text { ternas, definir restricciones y plantear opciones de solución a los problemas } \\
\text { identificados. } \\
\text { Definir alternativas y tomar decisiones en base a herramientas de II, estudio del } \\
\text { trabajo, gestión de operaciones, gestión del personal, gestión financiera y co- } \\
\text { mercial, gestión de proyectos y tecnología, técnicas complementarias como IO, } \\
\text { modelos matemáticos, psicología industrial, teoría de sistemas, a fin de generar } \\
\text { rendimiento y valor para la empresa. }\end{array}$ & Abogados \\
\hline 4. Mejora de la calidad de vida & $\begin{array}{l}\text { Estudiar, plantear y efectuar proyección a la comunidad, a fin de desarrollar } \\
\text { proyectos de mejora de calidad de vida a través del diseño, desarrollo y empren- } \\
\text { dimiento, dentro de modelos de desarrollo factible, deseable y sostenible. }\end{array}$ & $\begin{array}{l}\text { Economis- } \\
\text { tas, sociólo- } \\
\text { gos }\end{array}$ \\
\hline \multicolumn{3}{|c|}{ Escenario económico: poiesis, decisión y acción - La operación de sistemas empresariales } \\
\hline $\begin{array}{l}\text { Proceso de transformación } \\
\text { Producción y operación }\end{array}$ & $\begin{array}{l}\text { Gestión y control de operaciones, mediante la captación de materias primas, } \\
\text { personas y otros recursos tangibles e intangibles, su recepción, integración y } \\
\text { transformación en bienes o servicios, dentro de modelos circulares de produc- } \\
\text { ción, control y mejora }\end{array}$ & $\begin{array}{l}\text { Ingenieros } \\
\text { químicos, } \\
\text { logísticos, de } \\
\text { transporte }\end{array}$ \\
\hline $\begin{array}{l}\text { Cadena de suministro } \\
\text { Logística de entrada y salida }\end{array}$ & $\begin{array}{l}\text { Estructurar los niveles de resolución de problemas y alinear el flujo de los proce- } \\
\text { sos de materiales, de información y decisionales, mediante la integración de la } \\
\text { cadena de suministro, de manera que se ejecuten bien las decisiones correctas. } \\
\text { Control }\end{array}$ & $\begin{array}{l}\text { Adminis- } \\
\text { tradores, } \\
\text { contadores }\end{array}$ \\
\hline Calidad y mejora continua & $\begin{array}{l}\text { Diseñar, implantar y controlar los sistemas de control de procesos de manu- } \\
\text { factura, de control estadístico de calidad y de calidad total a fin de asegurar el } \\
\text { cumplimiento de los atributos y cualidades del producto, así como mantener } \\
\text { diferencias competitivas en el mercado }\end{array}$ & $\begin{array}{l}\text { Ingenieros } \\
\text { mecánicos, } \\
\text { electrónicos, } \\
\text { mecatróni- } \\
\text { cos }\end{array}$ \\
\hline
\end{tabular}

Fuente: Elaboración propia 
Esta actuación se complementa con la gestión en los sistemas empresariales y sus subsistema, que devienen en las áreas de trabajo del ingeniero industrial: operaciones, producción y control de calidad, creación de planta y proyectos, cadena de suministro y logística, comercialización y marketing, gestión de personal y seguridad, sistemas informáticos, planeamiento, finanzas.

\subsection{El ingeniero industrial en el proceso de re- solución de problemas}

Adicional a las tareas de diseño de sistemas empresariales, la resolución de problemas ha devenido en una de las actividades esenciales del trabajo del ingeniero industrial (5).

Existen diferencias conceptuales entre decidir y resolver. Tomar decisiones es elegir una opción para alcanzar un propósito. Resolver problemas es emplear métodos sistemáticos para definir situaciones problemáticas indeseadas, identificar problemas y eliminar las causas que la originan. Resolver problemas se refiere al reconocimiento de la necesidad de una decisión, analizar la situación, entender y sintetizar causas (S1) y efectos (S2), identificar problemas, elección de una alternativa y medidas de seguimiento de los resultados.

En la empresa se busca tomar decisiones para resolver problemas: sean conflictos (intereses de personas) o dilemas (asignación de recursos), con la finalidad de mantener o cambiar una situación existente (Cuadro 5).

Para enfrentar la problemática del mundo empresarial, se requiere un cambio de enfoque. Para esto, se han de identificar las variables relevantes de la situación problemática, a fin de prever los efectos derivados de soluciones parciales o problemas nuevos no previstos o no considerados. La indagación sobre situaciones problemáticas en el mundo de la empresa puede ser de cuatro formas: absolución, solución, disolución y resolución ${ }^{5}$.

Cuadro 5. Fines de las decisiones para resolver problemas del ingeniero industrial

\begin{tabular}{|c|c|c|c|c|c|c|}
\hline \multicolumn{2}{|c|}{ FOCO: } & \multicolumn{2}{|c|}{ PERSONAS } & \multicolumn{2}{|c|}{ COSAS (DILEMA) } & \\
\hline \multicolumn{2}{|c|}{$\begin{array}{l}\text { SITUACIÓN } \\
\text { PROBLEMÁTICA } \\
\text { (sistémico) }\end{array}$} & \multicolumn{2}{|c|}{$\begin{array}{c}\text { CONSENSUAR INTERESES } \\
\text { (CONFLICTO) } \\
\text { (propósito, fin, motivos, intereses) }\end{array}$} & \multicolumn{2}{|c|}{$\begin{array}{c}\text { ASIGNAR RECURSOS } \\
\text { (DILEMA) } \\
\text { (cantidad, disponibilidad, rendimiento) }\end{array}$} & \\
\hline \multicolumn{2}{|c|}{ INTERÉS } & $\begin{array}{l}\text { PERSONA } \\
\text { EN SÍ }\end{array}$ & TAREA & ESTABILIDAD & TRANSFORMAR & Labor del II \\
\hline \multicolumn{2}{|c|}{ Mantener } & Seguridad & Eficacia & Flujo & Resultados & $\begin{array}{l}\text { Gestión de la } \\
\text { operatividad }\end{array}$ \\
\hline \multirow{2}{*}{ Cambiar } & Mejorar & Capacitación & Productividad & Funcionamiento & Eficiencia & $\begin{array}{l}\text { Diseño de } \\
\text { sistemas }\end{array}$ \\
\hline & $\begin{array}{l}\text { Empeo- } \\
\text { rar }\end{array}$ & $\begin{array}{l}\text { Política de } \\
\text { partido }\end{array}$ & Boicot & Clientelaje & $\begin{array}{l}\text { Reforma o reor- } \\
\text { ganización }\end{array}$ & ¿...? \\
\hline
\end{tabular}

Según Ackoff (2000) un problema es una abstracción extraída de la experiencia real mediante al análisis, pero los problemas no están separados, sino, se presentan en situaciones que se componen de sistemas complejos de problemas con elevada interacción. El término situación problemática se refiere a sistemas de problemas, los cuales se pueden ver y resolver desde diferentes perspectivas y propósitos, según los decisores intervinientes.

Ackoff define las formas de enfrentar las situaciones problemáticas: a) Absolución, es ignorar el problema con la esperanza que se arreglará por sí solo o no empeorará, es el ceteris paribus o la eliminación de variables no relevantes, no definibles o no controlables, b) Solución, es el propósito de las herramientas de la teoría de decisiones que busca el mejor resultado imaginable, la solución, óptima o ideal, delimitando el alcance del problema y reduciéndolo a términos controlables, c) Disolución del problema, redefiniendo los componentes de la situación problemática de manera que modifique sus resultados o su desempeño, corresponde al diseño ideal de un nuevo sistema y su implantación, d) Resolución es hacer algo que permita un resultado aceptable y satisfactorio que funcione en la realidad, se sustenta en una visión integral de la problemática buscando la alternativa que mejore o modifique las variables pertinentes, previendo problemas emergentes derivados de fallas en la implantación de la opción 


\subsection{Las competencias del ingeniero industrial en la problemática empresarial}

El ingeniero industrial requiere competencias generales para la dirección de los recursos y las personas, competencias específicas para gerenciar sistemas empresariales y competencias enfocadas en problemas emergentes, nuevos o cíclicos (16), como se muestra en la Figura 7.

1) Competencias generales. Las competencias generales se ubican en el nivel estratégico de la resolución de problemas de la empresa. Este nivel es gerencial y busca la integración de las dimensiones de la empresa, para su funcionamiento eficaz y para obtener resultados esperados, bajo criterios de pragmatismo y utilitarismo empresarial. Lo fundamental para la dirección de recursos y personas se muestra en el Cuadro 6.
2) Competencias para gestionar sistemas empresariales. Estos procesos abarcan a la totalidad de la empresa y la organización en su conjunto. Su desenvolvimiento permite el funcionamiento y mejora de los sistemas empresariales en sus niveles operativos y directivos. Se muestra en el Cuadro 7.

3) Competencias para manejo de efectos emergentes. Surgen a partir de la complejidad del problema que se enfrenta. Estos efectos representan nuevos problemas, no previstos, no considerados, ocultos a la percepción por la cosmovisión del decisor. $\mathrm{O}$, de identificarse, se les considera estáticos, no relevantes o ceteris paribus. Cuando se les enfrenta se les considera fallas en la implantación de decisiones y, según la prioridad directiva, se les relega, minimiza o se ocultan. Ver el Cuadro 8.

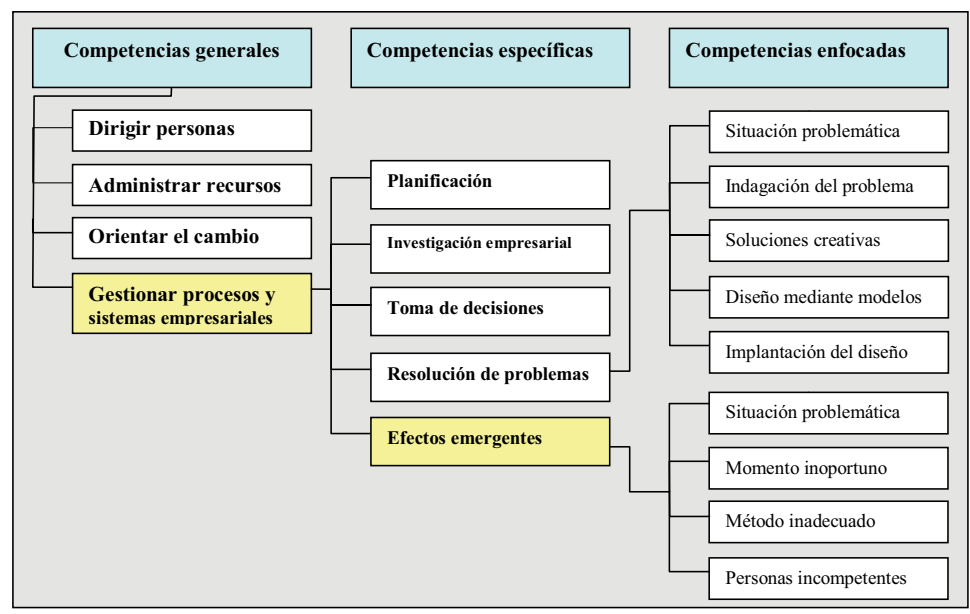

Cuadro 6. Competencias generales requeridas por el ingeniero industrial

\begin{tabular}{|l|l|l|}
\hline Competencia básica requerida & \multicolumn{1}{|c|}{ Concepto } & \multicolumn{1}{|c|}{ Procesos a manejar } \\
\hline $\begin{array}{l}\text { a. Competencia para dirigir } \\
\text { personas }\end{array}$ & $\begin{array}{l}\text { Orientar equipos de trabajo capaz y motivado para } \\
\text { obtener logros organizacionales concordantes con } \\
\text { sus metas personales. }\end{array}$ & $\begin{array}{l}\text { Se contempla: } \\
\text { - estilo } \\
\text { - motivación } \\
\text { - comunicación }\end{array}$ \\
\hline $\begin{array}{l}\text { b. Competencia para adminis- } \\
\text { trar recursos }\end{array}$ & $\begin{array}{l}\text { Diseñando la organización y la arquitectura de los } \\
\text { recursos tangibles e intangibles de la organiza- } \\
\text { ción, la cual está compuesta por personas, conoci- } \\
\text { mientos, recursos, inversiones, dinero y tiempo. }\end{array}$ & $\begin{array}{l}\text { - recursos tangibles } \\
\text { - recursos intangibles }\end{array}$ \\
\hline $\begin{array}{l}\text { c. Competencia para orientar } \\
\text { el cambio }\end{array}$ & $\begin{array}{l}\text { Generando valor agregado mediante la mejora y } \\
\text { renovación tecnológica y la innovación de produc- } \\
\text { tos y procesos. }\end{array}$ & $\begin{array}{l}\text { - innovación } \\
\text { - creatividad }\end{array}$ \\
\hline $\begin{array}{l}\text { d. Competencia para gestio- } \\
\text { nar sistemas empresariales }\end{array}$ & $\begin{array}{l}\text { El manejo sistemático de los procesos sistémicos } \\
\text { empresariales amplía las posibilidades de generar } \\
\text { resultados, ahorros y ganancias. }\end{array}$ & $\begin{array}{l}\text { 1) Planificación } \\
\text { 2) Investigación empresarial }\end{array}$ \\
3) Toma de decisiones \\
4) Resolución de problemas
\end{tabular}

Fuente: elaboración propia 
Cuadro 7. Competencias específicas para la gestión de sistemas empresariales

\begin{tabular}{|c|c|}
\hline Procesos sistémicos & Pasos del proceso / Fallas \\
\hline $\begin{array}{l}\text { 1. Proceso de planificación } \\
\text { El plan es la herramienta para } \\
\text { toma de decisiones. }\end{array}$ & $\begin{array}{l}\text { - Determinación de objetivos de la organización en unidades organizativas. } \\
\text { - Definir las habilidades del personal y propias para optimizar tiempo y recursos. } \\
\text { - Determinar las necesidades de la empresa y el personal. } \\
\text { - Desarrollo de los planes de acción para satisfacer necesidades de toda la organización. }\end{array}$ \\
\hline $\begin{array}{l}\text { 2. Proceso de investigación } \\
\text { empresarial }\end{array}$ & $\begin{array}{l}\text { - Enumerar y examinar los temas de estudio e interés de la organización. } \\
\text { - Determinar el tipo de temas de estudio que es necesario abordar. } \\
\text { - Priorizar los temas de estudio e investigación. } \\
\text { - Desarrollo de programas de investigación empresarial. } \\
\text { - Experimentación y desarrollo de herramientas de estudio de temas de empresa. } \\
\text { - Generación de innovación técnica, procesos de patentes y lanzamiento comercial. }\end{array}$ \\
\hline $\begin{array}{l}\text { 3. Proceso de toma de deci- } \\
\text { siones }\end{array}$ & $\begin{array}{l}\text { - Definir el problema que se resolverá y Delimitar el alcance de la decisión. } \\
\text { - Establecer criterios: factores realistas, mensurables y recursos disponibles. } \\
\text { - Definir los requerimientos obligatorios bajo criterios medibles. } \\
\text { - Definir y priorizar los criterios deseables. Identificar las alternativas. } \\
\text { - Determinar la viabilidad o factibilidad de las alternativas según criterios. } \\
\text { - Calificar las alternativas y seleccionar las de mayor calificación ponderada. } \\
\text { - Categorizar las alternativas seleccionadas según los criterios deseables. } \\
\text { - Determinar el riesgo (probabilidad) de estas alternativas } \\
\text { - Seleccionar la alternativa final más equilibrada. }\end{array}$ \\
\hline $\begin{array}{l}\text { 4. Proceso de resolución de } \\
\text { problemas }\end{array}$ & $\begin{array}{l}\text { - Identificación de la situación problemática } \\
\text { - Indagación del problema y recolección de la información necesaria. } \\
\text { - Búsqueda de soluciones creativas. Paso de idea a diseño mediante modelos matemáti- } \\
\text { cos. Evaluación y selección de la solución. } \\
\text { - Implantación del diseño }\end{array}$ \\
\hline $\begin{array}{l}\text { 5. Manejo de los efectos emer- } \\
\text { gentes }\end{array}$ & $\begin{array}{l}\text { - Derivadas de la decisión y elección de una solución. } \\
\text { - La resolución de problemas es compleja debido a diversas razones: Las fallas se refie- } \\
\text { ren a momento, situación, método, persona. }\end{array}$ \\
\hline
\end{tabular}

Fuente: Elaboración propia

\begin{tabular}{|l|l|}
\hline \multicolumn{2}{|l|}{ Cuadro 8. Competencias enfocadas al manejo de los efectos emergentes ${ }^{1}$} \\
\hline Complejidad del problema & Fallas en la resolución \\
\hline $\begin{array}{l}\text { La resolución de problemas es compleja debi- } \\
\text { do a diversas razones: }\end{array}$ & \\
- Información incompleta o insuficiente. & Las fallas son: \\
- Información confusa (tiempo insuficiente). & - Definición incorrecta de la situación problemática. \\
- Soluciones predefinidas de antemano. & - Momento inoportuno de implantación de las acciones co- \\
- Problemas cíclicos. Problemas complejos. & rrectivas. \\
- Problemas que se adaptan . & - Método o modelo inadecuado para resolver el problema. \\
- Problemas que se van automodificando. & - Personas incompetentes, sin capacidad o sin motivación \\
- Variables no controlables. & para aplicar la solución. \\
- Variables invisibles. Variable ceteris paribus. & \\
\hline
\end{tabular}

Fuente: Elaboración propia 


\section{CONCLUSIONES PRELIMINARES}

1. La Ingeniería Industrial es heredera del enfoque científico de Taylor, sus conceptos iniciales se enfocaron en la mejora de la tarea productiva en busca de la máxima eficiencia y productividad en el puesto de trabajo. Posteriormente, la profesión ha ido ampliando el alcance de sus técnicas y herramientas de mejora, surgiendo modelos enfocados en la gestión del proceso productivo, en el diseño de la capacidad y estructuras de producción, en la administración de los recursos humanos, hasta la estrategia de operaciones. Las nuevas visiones y perspectivas de la carrera han enriquecido la teoría y la praxis de la ingeniería industrial y han permitido una amplia visión conceptual y un alcance académico y profesional que cubre los niveles operativos, tácticos, directivos, estratégicos, e incluso conceptuales del funcionamiento de la empresa.

2. El ingeniero industrial emplea conceptos, técnicas y herramientas de la especialidad, agrupadas con diferentes denominaciones, como Gestión de operaciones u otras, aplicadas sobre sistemas de actividad humana, sean empresariales o sociales, a los que diseña, dirige y/o gestiona y sobre los que toma decisiones orientadas a resolver problemas y obtener resultados.

3. Uno de los principales ámbitos de aplicación de los conceptos y teoría de la Ingeniería Industrial es el modelamiento y gestión de sistemas de transformación, sean productivos o de servicios. La tendencia es al diseño, funcionamiento y manejo de sistemas de actividad humana, que trascienden de ámbito de la empresa. Pueden ser de ámbito operativo como la pequeña empresa, o de ámbito amplio, como los sistemas urbanos y de transporte, pueden ser de ámbito privado como la gestión de empresa global o de ámbito público, como el diseño de sistemas de negociación de externalidades entre gobierno local, mineras y gobierno central, o pueden ser sistemas cambiantes y evolutivos, como es el diseño de estrategias de operación para complejos mundiales de entretenimiento o la indagación de elementos de problemas perversos o casi insolubles, como los costos emergentes de actividades extractivas o el funcionamiento de los subrepticios sistemas de corrupción en los gobiernos. También pueden ser de ámbito concreto, como el diseño de servicios o de ámbito amorfo como el liderazgo y la dirección de personas.
4. La superior perspectiva y la capacidad de diseñar modelos e introducir mejoras en todos los niveles de resolución y en todos los sistemas de empresa, ha permitido un replanteamiento del rol del ingeniero industrial, en el diseño, la gestión y las decisiones en los sistemas de actividad humana, de todo tipo. En síntesis, el ingeniero industrial con mayor visión conceptual y amplio alcance académico y profesional, supera la eficacia de otras profesiones, también enfocadas en el funcionamiento de las organizaciones.

\section{REFERENCIAS BIBLIOGRÁFICAS}

[1] Acevedo, Adolfo (2009). "La resolución de problemas en el mundo de la empresa". Industrial Data Revista de Investigación, Vol. 12, № 2 , julio-diciembre 2009. UNMSM.

[2] Acevedo, Adolfo (2010). "El modelo conceptual de las 4 Dimensiones para la resolución de problemas". Industrial Data Revista de Investigación, Vol. 13, N² 2, julio-diciembre 2010. UNMSM.

[3] Ackoff, Russell (2000). Recreación de las corporaciones. Un diseño organizacional para el siglo $X X I$. Ed. Oxford University Press. México.

[4] Báez, Juan (2009). Investigación cualitativa. 2da. edición. ESIC Editorial. España.

[5] Billings, Junguzza, Poirier, Saeed (2005). "EI papel y la carrera profesionales del ingeniero industrial en la organización moderna", en Maynard, Manual del ingeniero Industrial. 5ta. edición. Mc Graw Hill, México.

[6] Blair y Whitston (1973). Elementos de Ingeniería de Sistemas Industriales. Editorial Prentice-Hall Internacional. España.

[7] Checkland y Scholes (1994). La metodología de los sistemas suaves de acción. Noriega Editores. México.

[8] Chiavenato, Idalberto (2004). Introducción a la teoría general de la administración. 7ma. Edición. Editorial Mc Graw Hill. México.

[9] Fayol, Henri (1961). "Administración industrial y general”. 1ra edición en español. México.

[10] Fundación Drucker (1998). La organización del futuro. Ed. GRANICA, Argentina.

[11] Hernández, Sampieri, Fernández y Baptista (2010). Metodología de la investigación. 5ta edición. Ed. Mcgraw-Hill, Chile. 
[12] Hodson, William (1996). Maynard Manual del Ingeniero Industrial. 4ta. edición. Ed. McgrawHill, México.

[13] Kast y Rosenzweig (1968). Administración en las organizaciones, enfoque de sistemas y de contingencias. Ed. Mcgraw-Hill, México.

[14] Krajewsky y Ritzman (2000). Administración de Operaciones. $5^{\mathrm{a}}$ edición. Pearson-Prentice Hall. México.

[15] Minztberg, Quinn y Voyer (1997). El proceso estratégico. Conceptos, contextos y casos. Prentice Hall. México.

[16] Read, James (2005). "El ingeniero industrial como administrador", en Maynard, Manual del ingeniero Industrial. 5ta.edicion. Mc Graw Hill, México
[17] Riggs, James (2001). Sistemas de Producción. Planeación Análisis y Control. Limusa Noriega Editores. México.

[18] Samuelson y Nordhaus (2002). Economía. $17^{\mathrm{a}}$ edición. Editorial Mc Graw Hill. España.

[19] Senge, Peter (1990). La Quinta disciplina. Gránica. España.

[20] Taylor, Frederick (1961). Principios de la administración científica. $1^{\text {a }}$ edición en español. México.

[21] Vaill, Peter (1967). "Industrial Engineering and Socio-Technical Systems", en Journal of Industrial Engineering, $N^{\circ}$ 9, vol. 16, USA.

[22] Zandin, Kjell (2005). Maynard Manual del ingeniero Industrial. 5ta. edición. Ed. McgrawHill, México. 